\title{
Controlling mineral polymorphs: insights from computer simulation.
}

\author{
VITTORIA FANTAUZZO, EMMA ARMSTRONG, \\ VESELINA MARINOVA, STEPHEN R YEANDEL, COLIN \\ FREEMAN AND PROF. JOHN H HARDING
}

University of Sheffield

Presenting Author: j.harding@sheffield.ac.uk

Understanding how the nucleation and growth of specific polymorphs can be controlled is an important objective in many fields. In biomineralisation, an enduring issue is how organisms control which polymorph of $\mathrm{CaCO}_{3}$ (calcite or aragonite) crystallises [1]. The local structure of amorphous $\mathrm{CaCO}_{3}$ is known to be important in the mineralisation process [2]. Industrially important minerals like $\mathrm{CaSO}_{4}$ exist in several phases. Bassanite forms first in aqueous solution and converts to the more stable gypsum by an unknown mechanism [3]. Heteronucleation of $\mathrm{KNO}_{3}$ has been studied and discussed using classical nucleation theory [4]. In this work we explore a range of factors that can control the polymorph selection and nucleation of mineral phases. To tackle these problems forcefields have been adapted $\left(\mathrm{CaCO}_{3}, \mathrm{CaSO}_{4}\right)$ or fitted from scratch $\left(\mathrm{KNO}_{3}\right)$ and shown to reproduce experimental data, particularly the solution thermodynamics.

We use new structural analysis methods (based on measures like the Manhattan distance) to identify clusters within the system that resemble calcite or aragonite. Results suggest inhibiting the crystallisation of one polymorph promotes it in the other. The calculated lifetimes also suggest that aragonitic clusters are much longer-lived than calcitic ones.

The detailed study of Hamm et al [5] supports the idea that "good binders are good nucleators". We have therefore calculated interfacial free energies for mineral/water systems to identify the most stable surfaces and simulated the ability of organic molecules and self-assembled monolayers (SAMs) to form stable interfaces with minerals. We have also examined how defects and disorder in flexible SAMs can affect the ability of ions to form clusters.

Finally, we consider whether kinetic or thermodynamic considerations dominate the choice of mechanism for nucleation and growth within the context of classical nucleation theory.

[1] M. Zeng et al. (2018), P.N.A.S. 115, 7670-7675.

[2] S.T. Mergelsberg et al. (2020), Cosmo. Geo. Acta 289, 196-206.

[3] A.E.S. Van Driessche et al. (2012), Science 336, 69-72.

[4] D. Selzer et al (2019), J. Cryst. Growth 517, 39-47.

[5] L.M. Hamm et al. (2014), P.N.A.S. 111, 1304-1309. 